International Journal of Engineering \& Technology, 7 (4.44) (2018) 233-236
International Journal of Engineering \& Technology
Website: $w$ ww.sciencepubco.com/index.php/IJET
Research paper

\title{
Thin Client System for Education Purpose using Raspberry Pi
}

\author{
Rini Handayani ${ }^{1}$, Simon Siregar ${ }^{2 *}$, Marlindia Ike Sari $^{3}$, Gaous Afrizal ${ }^{4}$ \\ ${ }^{1,2,3}$ School of Applied Science, Telkom University, Bandung, Indonesia \\ ${ }^{4}$ School of Electrical Engineering and Informatics, Bandung Institute of Technology, Bandung, Indonesia \\ *Corresponding author E-mail: simon.siregar@tass.telkomuniversity.ac.id
}

\begin{abstract}
Procurement of computers for infrastructure that supports learning in schools requires a lot of money. The application of the Computer Thin Client system can be an alternative solution to these problems. The use of thin client computers, can reduce resource use, so that it can make costs more efficient. The use of single board computers, is also a cost efficiency, as a substitute for computers. This system consists of one server and several single board computers as thin clients. In a Computer Thin Client network, the server has a very important role that functions as a processor and serves the activities of the client that performs the input / output process. This system also features a monitoring function to monitor the performance of resources from servers and client activities. In this study, the processes carried out by the development of server and client system infrastructure, build LTSP for the formation of thin clients and resource sharing, as well as the development of monitoring systems.
\end{abstract}

Keywords: Thin-Client; LTSP; Thinlinc; Multipoint Server; ThinStuff.

\section{Introduction}

The use of computers for schools, both elementary and high school, is considered very important. "Education Sector Analytical and Capacity Development Partnership (ACDP) Consultant Totok Amin Soefijanto said that the government needs to align technology in the world of education so that young people can compete when entering the era of the ASEAN Economic Community (MEA)" Jakarta, CNN Indonesia 2015. Information Technology Utilization and Communication (ICT) as a learning medium has begun to be applied in many schools in Indonesia. "The Head of the Education Information and Communication Technology (Pustekkom) Center of the Ministry of Education and Culture (Kemendikbud), Ari Santoso, said that the number of schools that apply ICT as learning media has increased significantly this year. Compared to three years ago, the number of schools using ICT now increased by 250 or amounting to 100,277 schools "SINDONEWS.com, 2014".

However, currently there are still many schools that have not used and used computers, especially in remote areas because of many problems, one of which is the absence or inadequate computer equipment that can be used because it requires a large amount of money to procure large amounts of Personal Computers (PCs).

The application of the Computer Thin Client system can be an alternative solution to these problems. This system consists of one server and several single board computers as thin clients. In a Computer Thin Client network, the server has a very important role that functions as a processor and serves the activities of the client that performs the input / output process. Therefore, the server requires very high processor and internal memory specifications and reliable software to maximize its function. This system also features a monitoring function to monitor the performance of resources from the server and client activities.

The construction of this thin client computer system can reduce the procurement and operational costs needed when compared to personal computers (PCs) for example in the construction of a computer laboratory in schools. It is expected that the implementation of this thin client computer can make a user feel the same experience using a personal computer (PC).

This system prototype was built by utilizing the resources owned by the server then the resources were utilized by thin clients through computer networks to process and input / output so that thin-clients have performance equivalent to standalone personal computers (PCs). This system prototype consists of: Server as the processing center for input / output from thin clients, Single board computer (SBC) as a thin client, Computer network infrastructure in the form of wired connection or wireless connection as a thin client communication line with the server, and resource sharing application on server and client.

\section{Internet of Thing}

Internet of Thing is a concept that extends the utilization of internet connectivity that is connected continuously. Originally introduced by Kevin Ashton at MIT, defining the Internet of Things, as a global network infrastructure, connects physical and virtual objects through data capture exploitation and communication capabilities. Infrastructure consists of existing networks and the internet and network development. All of this will offer object, sensor and connection capability identification as the basis for the development of independent co-operative services and applications. It is also characterized by high levels of autonomous data capture, event transfers, network connectivity, and interoperability.[1][2] 


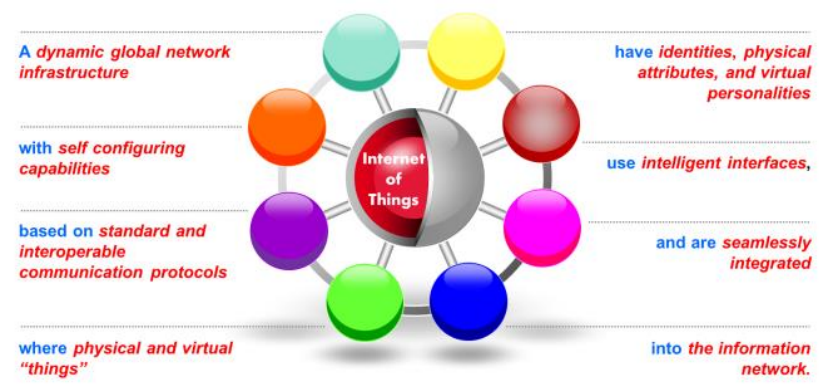

Fig. 1: IOT Definition[3]

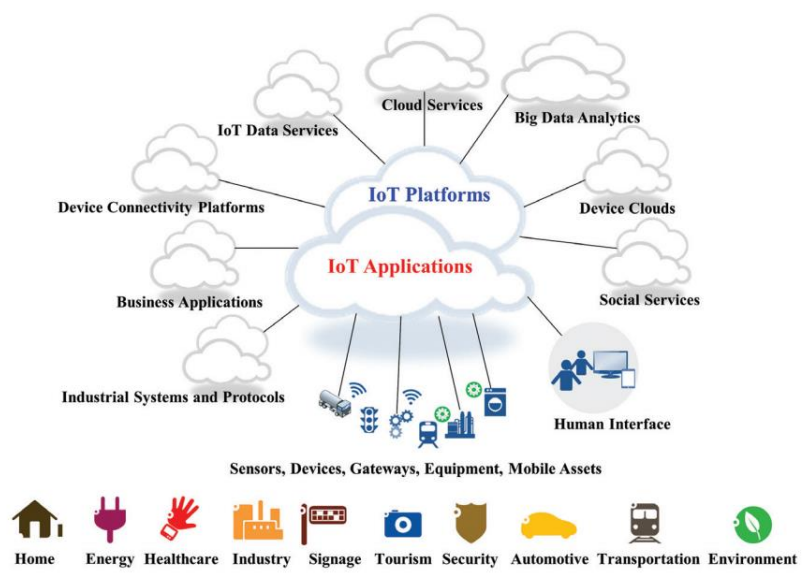

Fig. 2: IoT Integration [4]

\section{Thin Client Server Computing (TCSC)}

According to Joel Canter, a thin client network is a network environment where the client functions as a terminal that accesses data and applications from the server computer. The data processing process is done centrally by the server while the client only provides input from the keyboard and mouse and outputs in the form of a display or image (display).

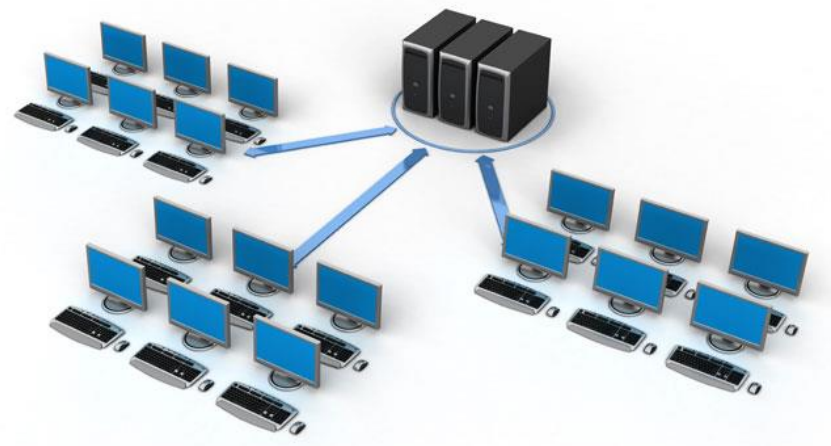

Fig. 3: Illustration of the Thin Client Server Computing[5]

In the first generation of computer networks, the concept of the Thin Client Server Computing (TCSC) has also been used and is better known as the dumb terminal, that is, the client is only used to input and view the processed server in the form of a display. One of the advantages of the Thin Client Server Computing concept is compatibility. Existing systems, such as client-servers, can be applied together on one network with the Thin Client Server Computing. Because in its application Thin Client Server Computing does not change the overall system or infrastructure that already exists. [6]

Thin Client is designed for the efficiency and full use of computing capabilities of server computers which are now more than enough to meet normal computing needs and on the other hand reduce overall device usage, maintenance and investment costs compared to fat client solutions. [7]

\subsection{Virtual Desktop Infrastructure (VDI)}

Virtual Desktop Infrastructure (VDI) is a virtualization technique that can access to the desktop. VDI is a desktop copy of the operating system, applications and documents, which is stored and run entirely from the server[8]. VDI provides services to clients to access virtual desktop services through a web browser interface. Recent study shows the performance of virtual desktop operating system in Virtual Desktop.[9]

\subsection{Linux Terminal Server Project (LTSP)}

Linux Terminal Server Project (LTSP) is a project to create servers on the Linux operating system platform. LTSP provides an easy way to use cheap servers with graphical and character interfaces on Linux servers.

With the LTSP application, clients with minimum capacity hard disk (diskless) can access Linux servers and run various applications on the server. With LTSP we can use low-end computers; without using a hard disk, floppy and CD-ROM; by only adding a bootable NIC. That way the procurement costs of the device can be minimized. [10]

\section{LTSP Design}

This LTSP system is a system that allows users with minimal resources such as raspberry-Pi to experience such as using a desktop computer. The experience of desktop computers is obtained from servers that are connected locally with thin clint. On the server side, a set of applications will be built that can be used by thin clients together through the local network. That is why users with minimal resources such as thin clients are very suitable to be applied in remote areas or for specific purposes such as book cata$\log$ search engines. This initial stage has several steps taken to achieve the development of systems and applications.[11]

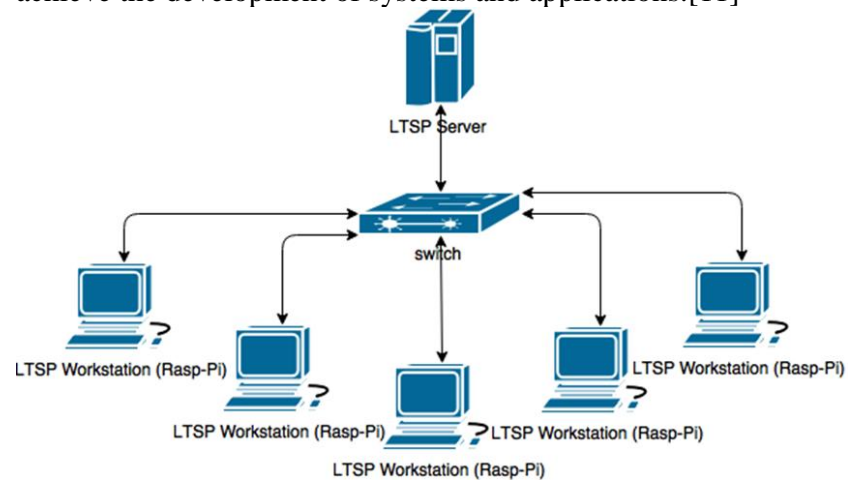

Fig. 4: Proposed Designing of Computer Thin Client with LTSP

The Server spesification which is used in this research is:

1. Intel Core i5-6600K 3.5Ghz Up To 3.9Ghz - Cache 6MB Socket LGA 1151 - Skylake Series

2. Motherboar LGA1151, Z170, DDR4

3. WDC 2.5" 1TB SATA $8 \mathrm{MB}$

4. DDR4 PC19200 8GB (1X8GB)

Raspberry Pi model $3 \mathrm{~B}+$ is used as the thin-client which has spesification as follows:

1. Broadcom BCM2837B0, Cortex-A53 (ARMv8) 64-bit $\mathrm{SoC} @ 1.4 \mathrm{GHz}$

2. 1GB LPDDR2 SDRAM

3. $2.4 \mathrm{GHz}$ and $5 \mathrm{GHz}$ IEEE $802.11 \mathrm{~b} / \mathrm{g} / \mathrm{n} / \mathrm{ac}$ wireless $\mathrm{LAN}$, Bluetooth 4.2, BLE

4. Gigabit Ethernet over USB 2.0 (maximum throughput 300 Mbps)

5. Full-size HDMI

6. 4 USB 2.0 ports 


\section{Experiment Result}

In this research, four Raspberry Pi Model $3 \mathrm{~B}+\mathrm{SBC}$ is used as the thin-client. Each thin-client will be tested during idle condition, running high definition video (VLC Application) and running office application (WPS Office Application). Figure 5 shows the proposed Computer Thin-Client System in this research where star topology used. This topology is used to facilitate development. This allows the addition of a client at a time.

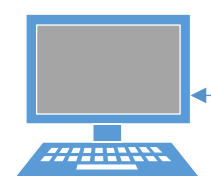

Raspberry Pi 3B+1 RPITC2

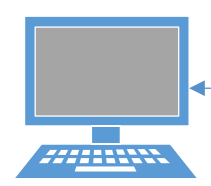

Raspberry Pi 3B+4 RPITC2

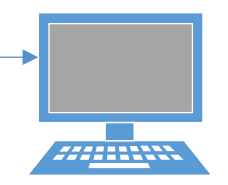

Raspberry Pi 3B+ 2 RPITC2

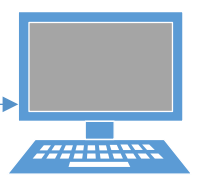

Raspberry Pi $3 \mathrm{~B}+3$ RPITC2
Fig. 5: The Proposed Computer Thin Client System

Figure 6 and 7 show the condition of application in thin-client while running an application. This is intended to see the client's performance in running applications both those applications that consume large resources such as multimedia applications and lightweight applications such as a word processor. Moreover figure 8 shows the idle condition in Windows Server.

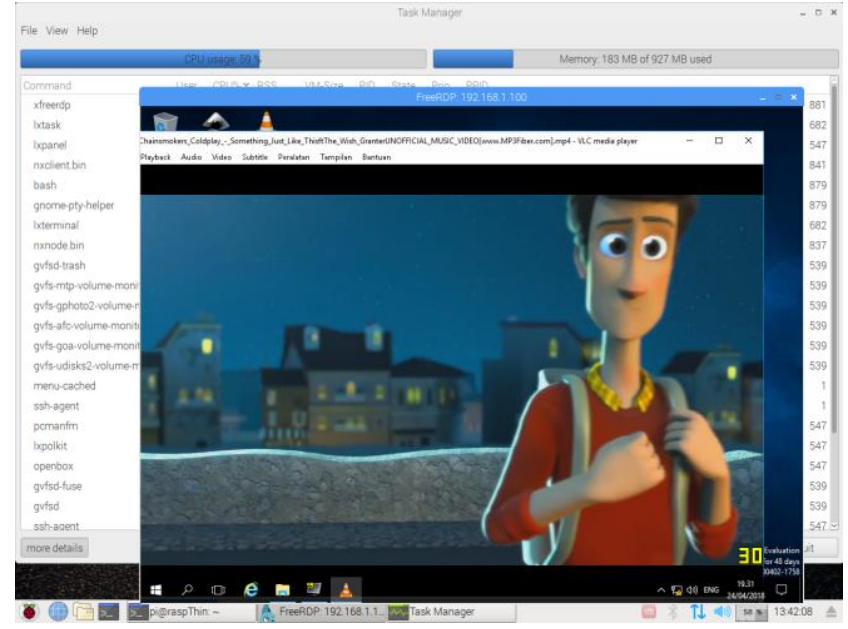

Fig. 6: Video application in thin-client with ThinStuff Server

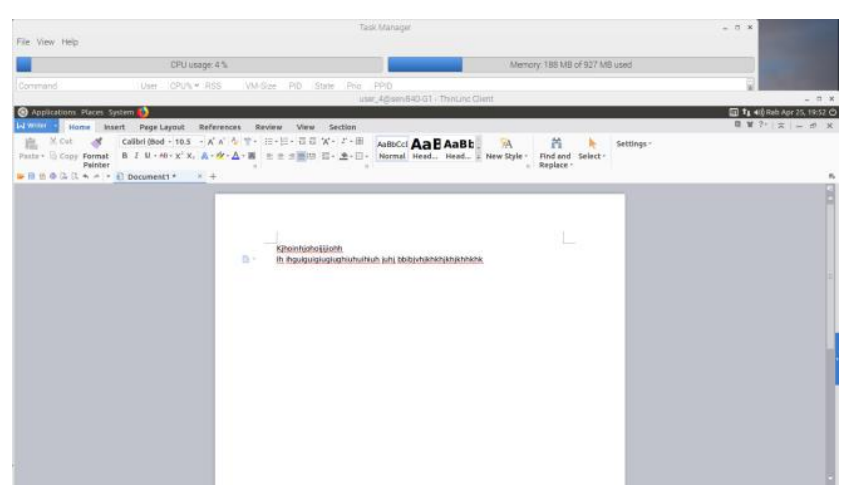

Fig. 7: Word processor application in thin-client with ThinLinc Server

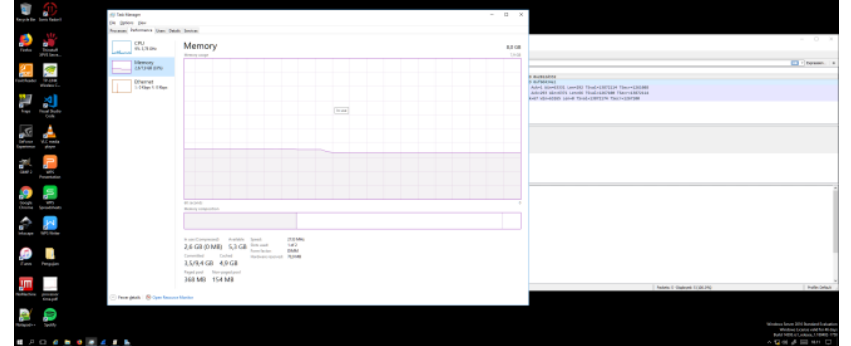

Fig. 8: Idle Condition in Multipoint Terminal Server (windows)

The result of the Thin Client system is shown in table 1, 2 and 3 for single user client using cable and using wireless communication with linux based server using $\mathrm{x} 2 \mathrm{go}$ and thinlinc.

Based on observations recorded in tables 1 and 2 (linux based server using X2GO) client performance is better by using a cable connection than wireless. And along with the increase in the number of clients connected to the server, performance in running the office application is not much different from only one client that is connected. Another case in running multimedia applications, the computing process on the $\mathrm{CPU}$ looks busier. Moreover, in running multimedia applications by using wireless by four clients at the same time, it doesn't even work at all to connect from server to client except linux based server using thinklinc.

Table 1: LAN (X2GO)

\begin{tabular}{|c|l|c|c|c|c|c|c|c|}
\hline \multirow{2}{*}{ No. } & \multirow{2}{*}{ Condition } & \multicolumn{5}{|c|}{ CPU $(\%)$} & MEMORY & \multicolumn{2}{c|}{ NETWORK (Bps) } \\
\cline { 2 - 9 } & 1 & 2 & 3 & 4 & $(\%)$ & Receive & Send \\
\hline 1 & 0 Idle & 3.0 & 0.0 & 0.0 & 19.0 & 15.8 & 0 & 0 \\
\hline 2 & 1 Video & 25.2 & 29.3 & 21.8 & 18.0 & 20.9 & $20.2 \mathrm{~K}$ & $1.0 \mathrm{M}$ \\
\hline 3 & 1 Word & 32.3 & 29.4 & 24.5 & 3.0 & 20.6 & $24.1 \mathrm{~K}$ & $914.2 \mathrm{~K}$ \\
\hline 4 & 4 IDLE & 22.8 & 3.0 & 7.8 & 2.0 & 31.5 & 340 & 714 \\
\hline 5 & 4 Video & 36.6 & 54.1 & 35.9 & 41.2 & 34.7 & $72.1 \mathrm{~K}$ & $3.6 \mathrm{M}$ \\
\hline 6 & 4 Word & 29.4 & 29.6 & 19.2 & 32.4 & 36.0 & $55.3 \mathrm{~K}$ & $2.1 \mathrm{M}$ \\
\hline
\end{tabular}

Table 2: wifi (X2GO)

\begin{tabular}{|c|l|c|c|c|c|c|c|c|}
\hline \multirow{2}{*}{ No. } & \multirow{2}{*}{ Condition } & \multicolumn{5}{|c|}{ CPU (\%) } & MEMORY & NETWORK (Bps) \\
\cline { 2 - 9 } & & 1 & 2 & 3 & 4 & $(\%)$ & Receive & Send \\
\hline 1 & 0 Idle & 9.9 & 29.4 & 5.9 & 16.8 & 31.0 & 0 & 0 \\
\hline 2 & 1 Video & 29.0 & 24.2 & 26.7 & 15.8 & 32.7 & $8.3 \mathrm{~K}$ & $586.7 \mathrm{~K}$ \\
\hline 3 & 1 Word & 23.8 & 8.1 & 13.7 & 12.0 & 31.8 & $7.5 \mathrm{~K}$ & $334.5 \mathrm{~K}$ \\
\hline 4 & 4 IDLE & 24.8 & 11.7 & 28.6 & 19.2 & 35.2 & $18.9 \mathrm{~K}$ & $1.1 \mathrm{M}$ \\
\hline 5 & 4 Video & 37.6 & 22.8 & 15.8 & 21.8 & 36.0 & $20.7 \mathrm{~K}$ & $998.9 \mathrm{~K}$ \\
\hline 6 & 4 Word & 11.0 & 9.7 & 26.7 & 9.3 & 31.7 & 0 & 0 \\
\hline
\end{tabular}

Table 3: wifi (thinlinc)

\begin{tabular}{|c|l|c|c|c|c|c|c|c|}
\hline \multirow{2}{*}{ No. } & \multirow{2}{*}{ Condition } & \multicolumn{9}{|c|}{ CPU (\%) } & \multicolumn{2}{c|}{ MEMORY } & \multicolumn{2}{|c|}{ NETWORK (Bps) } \\
\cline { 2 - 9 } & & 1 & 2 & 3 & 4 & $(\%)$ & Receive & Send \\
\hline 1 & 1 -idle & 2.0 & 13.0 & 10.0 & 19.2 & 23.7 & 367 & 0 \\
\hline 2 & 1 Video & 43.0 & 52.4 & 67.7 & 55.4 & 30.4 & $26.9 \mathrm{~K}$ & $1.9 \mathrm{M}$ \\
\hline 3 & 1 Word & 5.0 & 17.6 & 15.2 & 27.0 & 30.6 & $5.0 \mathrm{~K}$ & $40.8 \mathrm{~K}$ \\
\hline 4 & 2 -idle & 0.0 & 4.0 & 5.9 & 31.0 & 34.3 & 0 & 0 \\
\hline 5 & 2 Video & 63.3 & 71.7 & 67.0 & 71.3 & 36.5 & $70.8 \mathrm{~K}$ & $2.1 \mathrm{M}$ \\
\hline 6 & 2 Word & 0.0 & 36.0 & 28.1 & 30.6 & 35.7 & $19.1 \mathrm{~K}$ & $165.9 \mathrm{~K}$ \\
\hline 7 & 3 -idle & 8.0 & 0.0 & 1.0 & 18.0 & 32.1 & 0 & 0 \\
\hline 8 & 3 Video & 69.7 & 76.0 & 76.2 & 74.2 & 35.4 & $51.0 \mathrm{~K}$ & $1.4 \mathrm{M}$ \\
\hline 9 & 3 Word & 1.0 & 7.0 & 28.7 & 1.0 & 35.7 & $2.2 \mathrm{~K}$ & $26.6 \mathrm{~K}$ \\
\hline 10 & 4-Idle & 16.7 & 22.4 & 25.7 & 22.5 & 41.6 & $7.1 \mathrm{~K}$ & $59.5 \mathrm{~K}$ \\
\hline 11 & 4 Word & 30.4 & 21.8 & 23.8 & 20.0 & 41.5 & $13.4 \mathrm{~K}$ & $169 \mathrm{~K}$ \\
\hline 12 & 4 Video & 90.8 & 93.0 & 90.9 & 94.1 & 41.0 & $84.1 \mathrm{~K}$ & $2.8 \mathrm{M}$ \\
\hline
\end{tabular}

Moreover, the result of the Thin Client system is shown in table 4, 5 and 6 for single user client using cable and using wireless communication with windows-based server using Thinstuff and Multipoint terminal server.

Table 4: Using cable single user (Multipoint Terminal Server)
\begin{tabular}{|c|c|c|c|c|c|}
\hline \multirow{2}{*}{ User } & \multirow{2}{*}{ Condition } & \multirow{2}{*}{ CPU } & MEMORY & \multicolumn{2}{c|}{ NETWORK } \\
\cline { 3 - 6 } & & $(\%)$ & Receive (Bps) & Send(Bps) \\
\hline \multirow{3}{*}{1} & Idle & 7 & 33 & 0 & 0 \\
\cline { 2 - 6 } & Video & 22 & 34 & $48 \mathrm{~K}$ & $10.9 \mathrm{M}$ \\
\cline { 2 - 6 } & Word & 23 & 34 & 56 & 96 \\
\hline \multirow{2}{*}{2} & Idle & 13 & 37 & 0 & 0 \\
\cline { 2 - 6 } & Video & 39 & 39 & $104 \mathrm{~K}$ & $17.5 \mathrm{M}$ \\
\hline
\end{tabular}




\begin{tabular}{|c|c|c|c|c|c|}
\hline \multirow{2}{*}{ User } & \multirow{2}{*}{ Condition } & \multirow{2}{*}{ CPU } & MEMORY & \multicolumn{2}{|c|}{ NETWORK } \\
\cline { 4 - 6 } & & & $(\%)$ & Receive (Bps) & Send(Bps) \\
\cline { 2 - 6 } & Word & 24 & 38 & $72 \mathrm{~K}$ & $184 \mathrm{~K}$ \\
\hline \multirow{3}{*}{3} & Idle & 21 & 42 & 0 & $16.0 \mathrm{~K}$ \\
\cline { 2 - 6 } & Video & 50 & 43 & $200 \mathrm{~K}$ & $31.9 \mathrm{M}$ \\
\cline { 2 - 6 } & Word & 45 & 42 & $120 \mathrm{~K}$ & $272 \mathrm{~K}$ \\
\hline \multirow{3}{*}{4} & Idle & 13 & 43 & $8 \mathrm{~K}$ & $40 \mathrm{~K}$ \\
\cline { 2 - 6 } & Video & 72 & 48 & $224 \mathrm{~K}$ & $52 \mathrm{M}$ \\
\cline { 2 - 6 } & Word & 41 & 46 & $88 \mathrm{~K}$ & $344 \mathrm{~K}$ \\
\hline
\end{tabular}

Table 5: Using cable multiple user (Multipoint Terminal Server)

\begin{tabular}{|c|c|c|c|c|}
\hline Jumlah User & Condition & & CPU & Memory \\
\hline \multirow{4}{*}{1} & IDLE & & 7 & 33 \\
\cline { 2 - 5 } & VIDEO & & 21 & 34 \\
\cline { 2 - 5 } & WORD & & 19 & 34 \\
\hline \multirow{3}{*}{2} & IDLE & & 6 & 36 \\
\cline { 2 - 5 } & VIDEO & & 42 & 38 \\
\cline { 2 - 5 } & WORD & & 25 & 37 \\
\hline \multirow{3}{*}{3} & IDLE & & 9 & 41 \\
\cline { 2 - 5 } & VIDEO & & 54 & 43 \\
\cline { 2 - 5 } & WORD & & 56 & 43 \\
\hline \multirow{3}{*}{4} & IDLE & & 13 & 42 \\
\cline { 2 - 5 } & VIDEO & & 67 & 48 \\
\cline { 2 - 5 } & WORD & & 51 & 44 \\
\hline
\end{tabular}

Table 6: Using cable single user (ThinStuff)

\begin{tabular}{|c|c|c|c|c|c|}
\hline \multirow{2}{*}{ Tser } & \multirow{2}{*}{ Condition } & $\begin{array}{c}\text { CPU } \\
\text { Un }\end{array}$ & MEMORY & \multicolumn{2}{c|}{ NETWORK } \\
\cline { 3 - 6 } & & $(\%)$ & Receive (Bps) & Send(Bps) \\
\hline \multirow{3}{*}{1} & Idle & 1 & 29 & 0 & 0 \\
\cline { 2 - 6 } & Video & 18 & 32 & $48 \mathrm{~K}$ & $10.4 \mathrm{M}$ \\
\cline { 2 - 6 } & Word & 8 & 30 & $40 \mathrm{~K}$ & $744 \mathrm{~K}$ \\
\hline \multirow{3}{*}{2} & Idle & 3 & 34 & 0 & 0 \\
\cline { 2 - 6 } & Video & 36 & 41 & $160 \mathrm{~K}$ & $23.4 \mathrm{M}$ \\
\cline { 2 - 6 } & Word & 20 & 35 & $56 \mathrm{~K}$ & $920 \mathrm{~K}$ \\
\hline \multirow{3}{*}{3} & Idle & 7 & 37 & 0 & 0 \\
\cline { 2 - 6 } & Video & 53 & 39 & $136 \mathrm{~K}$ & $31.5 \mathrm{M}$ \\
\cline { 2 - 6 } & Word & 30 & 39 & $136 \mathrm{~K}$ & $432 \mathrm{~K}$ \\
\hline \multirow{3}{*}{4} & Idle & 1 & 29 & 0 & 0 \\
\cline { 2 - 6 } & Video & 64 & 46 & $160 \mathrm{~K}$ & $49.9 \mathrm{M}$ \\
\cline { 2 - 6 } & Word & 39 & 44 & $208 \mathrm{~K}$ & $1.7 \mathrm{M}$ \\
\hline
\end{tabular}

Table 7: Using cable cable multiple user (ThinStuff)

\begin{tabular}{|c|c|c|c|}
\hline \multirow{3}{*}{ User } & Condition & CPU $(\%)$ & Memory $(\%)$ \\
\hline \multirow{3}{*}{1} & IDLE & 2 & 34 \\
\cline { 2 - 4 } & VIDEO & 17 & 31 \\
\cline { 2 - 4 } & WORD & 5 & 30 \\
\hline \multirow{3}{*}{2} & IDLE & 2 & 34 \\
\cline { 2 - 4 } & VIDEO & 40 & 39 \\
\cline { 2 - 4 } & WORD & 12 & 35 \\
\hline \multirow{3}{*}{3} & IDLE & 2 & 34 \\
\cline { 2 - 4 } & VIDEO & 48 & 40 \\
\cline { 2 - 4 } & WORD & 19 & 38 \\
\hline \multirow{3}{*}{4} & IDLE & 2 & 34 \\
\cline { 2 - 4 } & VIDEO & 64 & 44 \\
\cline { 2 - 4 } & WORD & 41 & 43 \\
\hline
\end{tabular}

\section{Conclusion}

This research resulted in a thin-client prototype system that can work according to a design that can divide server resources into thin-clients through computer networks to process and input / output and have a performance equivalent to a standalone personal computer (PC). This system prototype consists of a server as a processing center and four Single board computers (SBC) as thin clients. In terms of overall system performance, maximum performance is still below $50 \%$ with four SBCs with video playback load (1080p HD quality). This system can still be upgraded to eight SBC.

\section{Acknowledgement}

This research is funded by Telkom University through "Penelitian Unggulan Universitas" scheme. We would like to thank the University for the Financial Support, and School of Applied Science Telkom University which provides testing ground for the implementation.

\section{References}

[1] Ziegler S, Nikoletsea S, Krco S, et al. Internet of Things and crowd sourcing - A paradigm change for the research on the Internet of Things. IEEE World Forum Internet Things, WF-IoT 2015 - Proc 2015; 395-399.

[2] Susanto D, Irdoni S, Rasyid MUH Al. Attendance report plugin for E-learning applications in PENS: (Based on moodle). Proc - Int Electron Symp Knowl Creat Intell Comput IES-KCIC 2017 2017; 2017-Janua: 153-160.

[3] Vermesan O, Harrison, Vogt M, Kalaboukas HK, et al. The Internet of Things - Strategic Research Roadmap. In: Cluster of European Research Projects on the IoT. 2009.

[4] Vermesan O, Friess P, Guillemin P, et al. Internet of Things beyond the Hype : Research, Innovation and Deployment. In: Building the Hyperconnected Society. 2015, pp. 15-118.

[5] Cisco-Reference. Campus LAN and Wireless LAN Design Guide, https://www.cisco.com/c/dam/en/us/td/docs/solutions/CRD/Jul2015 /CRD-Campus_LAN_Wireless_LAN_Design_Jul2105.pdf (2015).

[6] Hwang GH. Supporting cloud computing in thin-client/server computing model. Proc - Int Symp Parallel Distrib Process with Appl ISPA 2010 2010; 612-618.

[7] Ahlan AR Bin, Mahmud M, Arshad Y Bin. Conceptual architecture design and configuration of thin client system for schools in Malaysia: A pilot project. Proc 2010 Int Symp Inf Technol - Eng Technol ITSim'10 2010; 2: 952-955.

[8] Alagappan A, Venkataraman S, Sivakumar S. Virtual desktop infrastructure for rendering education technology in multifaceted learning platforms - A case study at Botho University. Int Conf Signal Process Commun Power Embed Syst SCOPES 2016 - Proc 2017; 1717-1720.

[9] Nakhai PH, Anuar NB. Performance evaluation of virtual desktop operating systems in virtual desktop infrastructure. 2017 IEEE Conf Appl Inf Netw Secur AINS 2017 2018; 2018-January: 1-6.

[10] Manvar D, Mishra M, Sahoo A. Low cost computing using virtualization for Remote Desktop. 2012 4th Int Conf Commun Syst Networks, COMSNETS 2012. Epub ahead of print 2012. DOI: 10.1109/COMSNETS.2012.6151364.

[11] Harsabat K. Rancang Bangun Jaringan Komputer Diskless Berbasis LTSP dengan Sistem Operasi Linux Ubuntu 14.04 LTS di Laboratorium Teknik Elektro UNNES. 